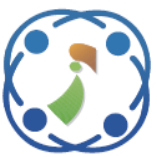

\title{
Application of Meta-Heuristic Algorithm for Finding the Best Solution for the Optimal Power Flow Problem
}

\author{
Thanh Long Duong ${ }^{1 *}$ \\ Ngoc Anh Nguyen ${ }^{1}$ \\ Thuan Thanh Nguyen ${ }^{1}$ \\ ${ }^{I}$ Faculty of Electrical Engineering Technology, Industrial University of Ho Chi Minh City, Vietnam \\ * Corresponding author's Email: duongthanhlong@iuh.edu.vn
}

\begin{abstract}
Optimal power flow (OPF) is an important problem in the power system operation. The purpose of the OPF problem is to optimize a defined objective function by modifying variables of control such as real power at generator buses except slack bus generator, voltages at all generator buses, reactive power of compensators and tap ratio of transformers while all constraints are satisfied. This paper is proposed an approach based on the artificial ecosystem optimization (AEO) to solve problem of optimal power flow. The suggested algorithm is tested on the IEEE-30 bus systems with five target functions consisting of fuel cost, emission, power loss, voltage deviations and L_index. The results obtained of the suggested AEO approach compared with equilibrium optimizer (EO), particle swarm optimization (PSO), sunflower optimization (SFO), genetic algorithm (GA) and other exiting methods. The results simulation shows that, standard deviation obtained value after 50 independent runs by the proposed AEO algorithm is better compared with EO, PSO, SFO and GA method. The fuel cost, emissions, active power loss and voltage deviations levels are reduced by $11.21 \%, 44.06 \%, 46.44 \%$, and $92.13 \%$ respectively, compared to the initial case. Furthermore, for other exiting methods the improvement level percentage (IL) of the proposed AEO algorithm can be up to $0.2285 \%$ for fuel cost objective, $0.137 \%$ for emission objective, $7.618 \%$ for total power loss objective, $89.85 \%$ for voltage deviation objective and $0.652 \%$ for $\mathrm{L} \_$index objective. Thus, the proposed AEO method is also one of effective and reliable algorithms for handling OPF problem.
\end{abstract}

Keywords: Artificial ecosystem optimization, Optimal power flow, Power loss, Generator cost.

\section{Introduction}

Optimal power flow (OPF) plays important role in operating and planning of power system. The OPF aims to optimize a defined objective by modifying variables of control such as real power at generator buses except slack bus generator, voltages at all generator buses, reactive power of compensators and tap ratio of transformers while satisfying constraints.

Many conventional approaches have been implemented for handling the OPF problem such as linear programming (LP) [1], nonlinear programming (NLP) [2], newton-based technique [3], quadratic programming (QP) [4], and interior point (IP) methods [5]. However, the objective functions of the OPF problem, which was solved by these conventional methods, is simple and differentiable. In fact, the OPF problem in modern power systems is always a nonlinear optimization problem and may be a non-differentiable one, thus it is an actual challenge for optimization methods for dealing with, especially the conventional methods

To over the limitations of classical methods, heuristic methods have been considered as alternative approaches to solve the OPF problem with the advantages of obtaining nearly optimum solution whether the problem is differentiable or not. Many heuristic optimization methods have applied for solving OPF problem such as tabu search (TS) [6], evolutionary programming (EP) [7], differential evolution (DE) [8], biogeography optimization (BOA) [9], teaching learning optimization algorithm (TLOA) [10], stud krill herd algorithm (SKHA) [11], water wave optimization algorithm (WWOA) [12], gravitational search algorithm (GSA) [13], artificial bee colony approach (ABCA) [14], moth swarm algorithm (MSA) [15], Jaya algorithm [16]. Besides, 
number of improved version of heuristic optimization algorithms have been proposed to improve the performance as well as robustness such as selfadaptive differential evolution (SADE) [17], modified differential evolution algorithm (MDEA) [18], enhanced genetic algorithm (EGA) [19], adaptive real coded biogeography-based optimization (ARCBOA) [20], improved stud krill herd algorithm (ISKHA) [21], improved grey wolf optimization (IGWO) [22], modified shuffle frog leaping algorithm (MSFLA) [23], modified imperialist competitive algorithm (MICA) [24], modified artificial bee colony approach (MABCA) [25], improved electromagnetism mechanism approach (IEMA) [26], modified of sine-cosine approach (MSCA) [27], hybrid particle swarm optimization and differential evolution (HPSO-DE) [28], hybrid particle swarm optimization and gravitational search approach (HPSO-GSA) [29].

In generally, these methods have successfully applied for the OPF problem, however they have always been a trade-off exploration and exploitation problem. Therefore, it might be challenging for many algorithms to obtain balance between exploration and exploitation abilities. Recently, an artificial ecosystem optimization (AEO) approach developed based on the flow of energy in the ecosystem is introduced in [30, 31]. The AEO method utilizes three mechanisms in the ecosystem to keep a problem of balancing exploration and exploitation ability that can over local minima. The ecosystem is considered as a population containing of a production organism, a decomposition organism and consumption organisms. The exploration mission is performed during the processing of consumption organisms via updating new solution and selecting the smallest energy level value. Unlike different many algorithms, the AEO does not need special control parameters in the calculation process. The AEO only requires two external parameters to control is that population size and maximum iterations number, so it is simple to implement and smooth execution. From this viewpoint, this paper proposed the AEO technique for dealing with the OPF problem with five different objective functions. The suggested technique is simulated on IEEE-30 bus system. The achieved result values of suggested technique compared with different techniques that shows the AEO also is an effective method to solve OPF problem in large scale and complex systems.

The main contributions of the study can be briefed as follows:

(i) The AEO is successfully adjusted for handling the OPF problem with five other target functions. (ii) The OPF method based on AEO have been successfully implemented for finding the optimal solution on IEEE 30-bus systems.

(iii) The effectiveness of the AEO technique is compared to the implemented methods and different exiting methods that prove the effectiveness of AEO for the problem of OPF.

\section{Problem formulation}

OPF is an optimization issue in electric power system operation which minimizes the defined objective functions by adjusting controlled variables while satisfying all security constraints of electric power system [11]. The problem of OPF is mathematically presented as below

$$
\min =F(x, u)
$$

Subject to

$$
\begin{aligned}
& g(x, u)=0 \\
& h(x, u) \leq 0
\end{aligned}
$$

Where $\mathrm{F}$ is the objective function; $g(x, u)$ and $h(x, u)$ are equality and inequality constraints, respectively. The state variables vector $\mathrm{x}$ and control variables vector $\mathrm{u}$ can be described as Eq. (4) and Eq. (5) respectively.

$$
\begin{array}{r}
x=\left[P_{G, \text { slack }}, V_{L 1}, \ldots, V_{L N_{L}}, Q_{G 1}, \ldots, Q_{G N_{G}},\right. \\
\left.S_{l} \ldots, S_{N_{l}}\right] \\
u=\left[P_{G i}, \ldots, P_{G N_{G}}, V_{G 1}, \ldots, V_{G N_{G}}, T_{1}, \ldots, T_{N_{T}},\right. \\
\left.Q_{c 1}, \ldots, Q_{c N_{c}}\right]
\end{array}
$$

\subsection{OPF objective functions}

In this study, five target functions including of fuel cost, emission cost, power loss, voltage deviations and L_index are considered as follows

\subsubsection{Fuel cost}

$$
O F_{F}=f_{i}\left(P_{G i}\right)=\sum_{i=1}^{N_{G}} a_{i}+b_{i} P_{i}+c_{i} P_{G i}^{2}
$$

Where $a_{i}, b_{i}, c_{i}$ are the fuel cost coefficients of the $i_{t h}$ generator.

\subsubsection{Emission}

Two important types SOx and NOx of emission gasses are calculated as the pollutant gasses. The 
emission gasses generated by each generating unit may be approximated by a combination of a quadratic cost and an exponential function of generator active power output. The emission is defined as Eq. (7)

$$
O F_{E}=\sum_{i=1}^{N_{G}}\left(\alpha_{i}+\beta_{i} P_{i}+\gamma_{i} P_{G i}^{2}+\xi_{i}\left(\lambda_{i} P_{G i}\right)\right)
$$

Where $\beta_{i}, \gamma_{i}, \xi_{i}$ are the emission coefficients of the $i_{\text {th }}$ generator

\subsubsection{Total transmission loss}

Total power loss is presented as Eq. (8)

$$
O F_{L}=\sum_{i=1}^{N_{G}} P_{G i}-\sum_{j=1}^{N_{L}} P_{D j}
$$

\subsubsection{Voltage deviation}

This objective is to minimize voltage deviation at all load buses and is described as Eq. (9)

$$
O F_{V}=\sum_{i=1}^{N_{L}}\left|V_{L i}-1.0\right|
$$

\subsubsection{Voltage stability enhancement}

Voltage stability is one of the important problems which needs to consider for operating of electric power system. To evaluate voltage stability, L-index known as voltage collapse proximity indicator. The bus with the highest $\mathrm{L}$-index value will be the most vulnerable bus in the system. The L-index calculation for a power system is presented as follow [14].

$$
\left[\begin{array}{c}
I_{G} \\
I_{L}
\end{array}\right]=\left[\begin{array}{ll}
Y_{G G} & Y_{G L} \\
Y_{L G} & Y_{L L}
\end{array}\right]\left[\begin{array}{c}
V_{G} \\
V_{L}
\end{array}\right]
$$

In which:

$I_{G}$ : Current at generator bus

$I_{L}:$ Load bus load

$V_{G}$ : Generator bus voltage

$V_{L}$ : Load bus voltage

Rearrange Eq. (10)

$$
\left[\begin{array}{l}
V_{L} \\
I_{G}
\end{array}\right]=\left[\begin{array}{ll}
Z_{L L} & F_{L G} \\
K_{G L} & Y_{G G}
\end{array}\right]\left[\begin{array}{c}
I_{L} \\
V_{G}
\end{array}\right]
$$

With

$$
F_{L G}=-\left[Y_{L L}\right]^{-1}\left[Y_{L G}\right]
$$

L index at load bus $\mathrm{j}$ can be calculated as follows

$$
L_{j}=\left|1-\sum_{i=1}^{N_{G}} F_{j i} \frac{V_{i}}{V_{j}} \angle \theta_{i j}+\theta_{i}-\theta_{j}\right|,
$$

Where $V_{i}, \delta_{i}$ are voltage and voltage angle at generator bus $i ; V_{j}, \delta_{j}$ are voltage and voltage angle at load bus $j ; \theta_{i j}$ is the phase-angle of $F_{j i}, N_{L}$ is the load buses. The objective function can be given as

$$
O F_{I L}=\max \left(L_{j}\right)
$$

\subsection{Constraints}

\subsubsection{Equality constraints}

Constraints on real and reactive power balance

$$
\begin{aligned}
& P_{i}=P_{G i}-P_{D i}= \\
& V_{i} \sum_{j=1}^{N}\left|Y_{i j}\right|\left|V_{j}\right| \cos \left(\delta_{i}-\delta_{j}-\theta_{i j}\right) \\
& Q_{i}=Q_{G i}-Q_{D i}= \\
& V_{i} \sum_{j=1}^{N}\left|Y_{i j}\right|\left|V_{j}\right| \sin \left(\delta_{i}-\delta_{j}-\theta_{i j}\right)
\end{aligned}
$$

\subsubsection{Inequality constraints}

The limits of power generation

$$
\begin{gathered}
P_{G i}^{\min } \leq P_{G i} \leq P_{G i}^{\max }, i=1,2, \ldots, N_{G} \\
Q_{G i}^{\min } \leq Q_{G i} \leq Q_{G i}^{\max }, i=1,2, \ldots, N_{G}
\end{gathered}
$$

The voltage limits of generator buses and load buses

$$
\begin{aligned}
& V_{G i}^{\min } \leq V_{G i} \leq V_{G i}^{\max }, i=1,2, \ldots, N_{G} \\
& V_{L i}^{\min } \leq V_{L i} \leq V_{L i}^{\max }, i=1,2, \ldots, N_{L}
\end{aligned}
$$

The capacity of switchable capacitor

$$
Q_{c i}^{\min } \leq Q_{c i} \leq Q_{c i}^{\max }, i=1,2, \ldots, N_{c}
$$

The limits of transformer tap

$$
T_{k}^{\min } \leq T_{k} \leq T_{k}^{\max }, k=1,2, \ldots, N_{T}
$$

The line flow limits of transmission line 


$$
S_{l} \leq S_{l}^{\max }, l=1,2, \ldots, N_{l}
$$

\section{Implementation of AEO for solving the OPF problem}

AEO is a method that are inspired by the flow of energy in a food chain. The AEO utilizes three mechanisms in the ecosystem to keep a problem balancing exploration and exploitation ability. The ecosystem is considered as a population containing of a production organism, a decomposition organism and consumption organisms. The energy level of each organism is based on its fitness value. The organism with better fitness value has higher energy level. The step by step of applying of AEO for the OPF problem is presented as follow

Step 1: Choose control parameter: Ecosystem size $n$, max iteration $t_{\max }$

Step 2: Initialize the ecosystem

Each solution (sol) is considered as an organism in the ecosystem and is initialized as follows

$$
\begin{aligned}
& \operatorname{sol}_{i, d}=\operatorname{sol}_{d, \min }+\operatorname{rand}(0,1)\left(\operatorname{sol}_{d, \max }-\right. \\
& \left.\operatorname{sol}_{d, \min }\right)
\end{aligned}
$$

Where, sol $_{d, \min }$ is the ith solution, $\mathrm{d}$ is the number of control variables, sol $_{d, \max }$ and sol $_{d, \min }$ are the upper and lower limits of $d$ th control variable which are defined as Eq. (4).

$$
\left\{\begin{array}{c}
\operatorname{sol}_{d, \min }=\left[P_{G 2}^{\min }, \ldots, P_{G N_{G}}^{\min }, V_{G 1}^{\min }, \ldots, V_{G N_{G}}^{\min },\right. \\
\left.T_{1}^{\min }, \ldots, T_{N_{T}}^{\min }, Q_{c 1}^{\min }, \ldots, Q_{c N_{c}}^{\min }\right] \\
\operatorname{sol}_{d, \max }=\left[P_{G 2}^{\max }, \ldots, P_{G N_{G}}^{\max }, V_{G 1}^{\max }, \ldots, V_{G N_{G}}^{\max }\right. \\
\left.T_{1}^{\max }, \ldots, T_{N_{T}}^{\max }, Q_{c 1}^{\max }, \ldots, Q_{c N_{c}}^{\max }\right]
\end{array}\right.
$$

Step 3: Solve power flow and evaluate the fitness function using Eq. (25) based on the energy level of the organism sol $_{i}$. The organism with the smallest fitness value is considered as the best organism in the ecosystem ( sol $\left._{\text {best }}\right)$.

$$
\begin{aligned}
O F_{i}^{(0)}=O F+ & I_{P}\left(P_{G 1}-P_{G 1}^{l i m}\right)^{2} \\
& +I_{q} \sum_{i=1}^{N_{G}}\left(Q_{G i}-Q_{G i}^{l i m}\right)^{2} \\
& +I_{v} \sum_{i=1}^{N_{L}}\left(V_{L i}-V_{L i}^{l i m}\right)^{2} \\
& +I_{S} \sum_{i=1}^{N_{T L}}\left(S_{l}-S_{l, \text { max }}\right)^{2}
\end{aligned}
$$

Where, $\mathrm{OF}$ is the objective function of each case $\left(\mathrm{OF}_{\mathrm{F}}, \mathrm{OF}_{\mathrm{E}}, \mathrm{OF}_{\mathrm{L}}, \mathrm{OF}_{\mathrm{V}}, \mathrm{OF}_{\mathrm{IL}}\right)$ that is defined by equation (6)-(9) and (13). $I_{p}, I_{q}, I_{v}$, and $I_{s}$ are the penalty coefficients for the inequality constraints of the state variables.

Step 4: Update the production organism

All rearrange organisms in direction of increasing energy level. The first organism which has lowest energy level is chosen as production organism. The production organism is updated as below

$$
\begin{gathered}
\operatorname{sol}_{1}^{\text {new }}=\operatorname{rand}_{1}(0,1) \cdot\left[1-\left(1-\frac{t}{t_{\text {max }}}\right)\right] \cdot \text { sol }_{\text {best }} \\
+\left(1-\frac{t}{t_{\text {max }}}\right) \cdot\left[\operatorname{rand}_{2}(0,1) \cdot\left(\operatorname{sol}_{d}^{\text {max }}-\operatorname{sol}_{d}^{\text {min }}\right)+\right. \\
\left.\operatorname{sol}_{d}^{\text {min }}\right]
\end{gathered}
$$

Step 5: Update the consumption organisms

Update the consumption organisms is based on three types of herbivores, carnivore and omnivorous. If the consumption organism is an herbivore, it will update with the production organism as Eq. (27)

$$
\begin{gathered}
\operatorname{sol}_{i}^{\text {new }}=\operatorname{sol}_{i}+\beta_{c^{\cdot}}\left(\operatorname{sol}_{i}-\operatorname{sol}_{1}^{\text {new }}\right) ; i \\
\in[2, \ldots, n]
\end{gathered}
$$

Where, $\beta_{c}$ is the consumption coefficient determined based on the Levy distribution as follow

$$
\beta_{c}=\frac{1}{2} \cdot \frac{u_{1}}{u_{2}} ; u_{1}, u_{2} \sim \mathrm{N}(0,1)
$$

Where, $N(0,1)$ is a standard normal distribution. If the consumption organism is a carnivore, it will update with another carnivore with higher energy level as Eq. (29)

$$
\operatorname{sol}_{i}^{\text {new }}=\operatorname{sol}_{i}+\beta_{c} \cdot\left(\operatorname{sol}_{i}-\operatorname{sol}_{j}\right)
$$

If the consumption organism is omnivorous, it will update with a producer and a carnivore with higher energy level as Eq. (30)

$$
\begin{aligned}
\operatorname{sol}_{i}^{\text {new }}= & \operatorname{sol}_{i}+\beta_{c} \cdot\left[\operatorname{rand}_{2}(0,1) \cdot\left(\operatorname{sol}_{i}-\operatorname{sol}_{1}^{\text {new }}\right)\right. \\
& \left.+1-\operatorname{rand}_{2}(0,1) \cdot\left(\operatorname{sol}_{i}-\operatorname{sol}_{j}\right)\right]
\end{aligned}
$$

Step 6: Solve power flow and evaluate the fitness function using Eq. (25) based on the energy level of the new organisms sol $i$

Step 7: Replace all organisms if new organisms have better fitness values

If new organisms have the better quality than the corresponding ones in the ecosystem, the selective mechanism is used to update the ecosystem and the 


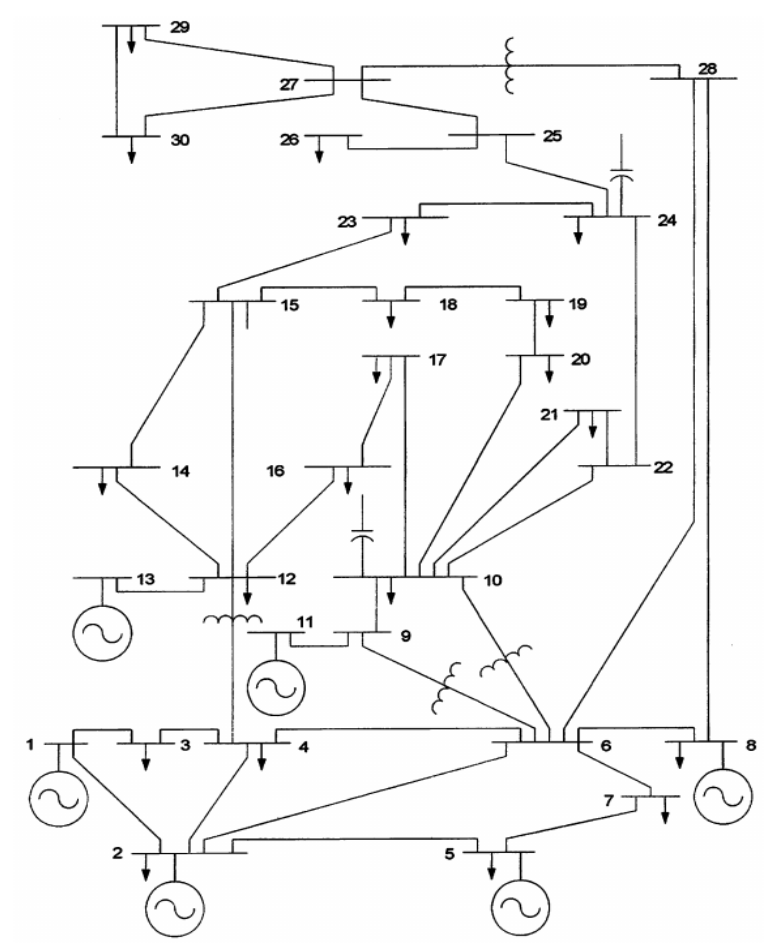

Figure. 1 The IEEE 30-bus system

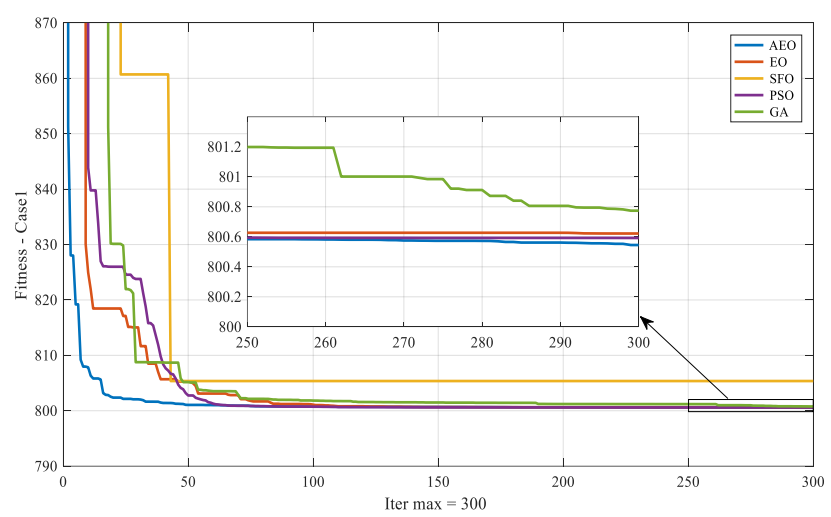

Figure 2. Convergence rate of the AEO and other methods for case 1

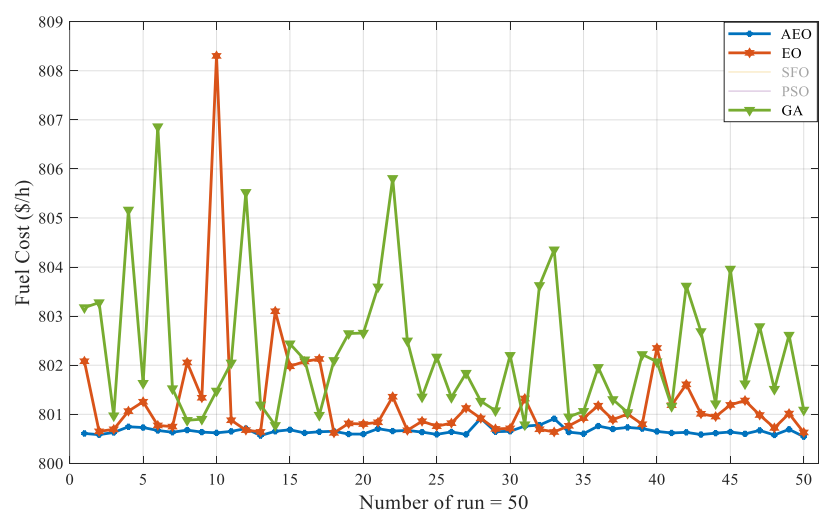

Figure 3. Fuel cost obtained in 50 runs using AEO and other approaches

best organism sol best is also updated after the ecosystem updated.
Step 8: Update the whole ecosystem by decomposition mechanism

Organisms that die will be decomposed by a decomposition organism. Therefore, each organism in the ecosystem will update with the decomposition organism as follows

$$
\operatorname{sol}_{i}^{\text {new }}=\operatorname{sol}_{i}+3 \cdot \beta_{d r} \cdot\left(\sigma_{1} \cdot \operatorname{sol}_{\text {best }}-\sigma_{2} \cdot \text { sol }_{i}\right)
$$

Where, $\beta_{d r}$ is the decomposition rate determined by $\beta_{d r} \sim N(0,1), \sigma_{1}$ and $\sigma_{2}$ are weight factors which are determined by the below equations

$$
\left\{\begin{array}{l}
\sigma_{1}=\operatorname{rand}_{3}(0,1) \cdot \operatorname{randi}([1,2])-1 \\
\sigma_{2}=2 \cdot \operatorname{rand}_{3}(0,1)-1
\end{array}\right.
$$

Step 9: Solve power flow and evaluate the fitness function using Eq. (25). The ecosystem and the best organism sol best $_{\text {be also updated. }}$ are

Step 10: Check stopping criteria. If $\left(t<t_{\max }\right)$ return to step 5 with $t=t+1$, otherwise go to next step.

Step 11: End. Export best organism

The best organism sol best $_{\text {corresponding to the }}$ value of the fitness function $F_{\text {best }}$ is considered as the result of the OPF problem.

\section{Numerical results}

The OPF problem with five different objective functions based on AEO method is developed on Matlab software to determine the optimal solution for IEEE-30 bus system. Furthermore, the obtained results using AEO are also compared with other studies to prove the effectiveness of the OPF problem method based on AEO.

The IEEE 30-bus system consist of six generators, 24 load buses and 41 lines as Fig 1. Bus $1,2,5,8,11$ and 13 are generator buses. Line 6-9, 6$10,4-12$ and $27-28$ is tap changer of transformers. In addition, bus 10, 12, 15, 17, 20,21, 23, 24 and 29 are reactive power sources. System data is given in [25, 32]. The generator buses voltage bound is within 0.95 and $1.1 \mathrm{p} . \mathrm{u}$, while load bus voltage limits are 0.95 and 1.05 p.u, the tap ratio bound is 0.9 and $1.1 \mathrm{p} . \mathrm{u}$, the reactive power sources capacity is [0-5] MVAr. The generation cost and emission coefficients of IEEE-30 bus system given in Table 1 .

The Table 2 is presented the control parameters and optimal value obtained using AEO method with five targets including of fuel cost, emission, active power loss, voltage deviations and $L \_$index. The values obtained of AEO method compared with EO, PSO, SFO and GA methods for every the objective 
Table 1. IEEE 30-bus system: fuel cost and emissions constants [25, 32]

\begin{tabular}{|l|l|l|l|l|l|l|l|l|l|}
\hline Generator & Bus & $\mathrm{a}$ & $\mathrm{b}$ & $\mathrm{c}$ & $\alpha$ & $\beta$ & $\gamma$ & $\zeta$ & $\lambda$ \\
\hline G1 & 1 & 0 & 2 & 0.00375 & 4.091 & -5.554 & 6.490 & 0.0002 & 2.857 \\
\hline G2 & 2 & 0 & 1.75 & 0.0175 & 2.543 & -6.047 & 5.638 & 0.0005 & 3.333 \\
\hline G5 & 5 & 0 & 1 & 0.0625 & 4.258 & -5.094 & 4.586 & 0.000001 & 8 \\
\hline G8 & 8 & 0 & 3.25 & 0.00834 & 5.326 & -0.0355 & 3.380 & 0.002 & 2 \\
\hline G11 & 11 & 0 & 3 & 0.025 & 4.258 & -0.05094 & 4.586 & 0.000001 & 8 \\
\hline G13 & 13 & 0 & 3 & 0.025 & 6.131 & -0.05555 & 5.151 & 0.00001 & 6.667 \\
\hline
\end{tabular}

Table 2. The control parameters and optimal value obtained using AEO method for five targets in IEEE 30-bus system

\begin{tabular}{|c|c|c|c|c|c|c|c|}
\hline \multirow[b]{2}{*}{$\begin{array}{l}\text { Control } \\
\text { parameters }\end{array}$} & \multicolumn{2}{|c|}{ Limits } & \multicolumn{5}{|c|}{ Proposed AEO Method } \\
\hline & Min & Max & $\begin{array}{c}\text { Fuel cost } \\
\text { Case } 1\end{array}$ & $\begin{array}{c}\text { Emissions } \\
\text { Case } 2\end{array}$ & $\begin{array}{l}\text { Power Loss } \\
\text { Case } 3\end{array}$ & $\begin{array}{l}\text { Voltage deviation } \\
\quad \text { Case } 4\end{array}$ & $\begin{array}{l}\text { L_index } \\
\text { Case } 5\end{array}$ \\
\hline P1(MW) & 50 & 200 & 177.1564 & 64.2336 & 51.6600 & 100.6993 & 162.9103 \\
\hline P2(MW) & 20 & 80 & 49.1070 & 67.4432 & 79.9791 & 77.6726 & 45.1485 \\
\hline P5(MW) & 15 & 50 & 21.3021 & 49.9976 & 49.9995 & 38.9237 & 19.8578 \\
\hline P8(MW) & 10 & 35 & 21.0267 & 34.9994 & 34.9861 & 20.4162 & 24.8632 \\
\hline P11(MW) & 10 & 30 & 11.8464 & 29.9978 & 29.9344 & 22.4628 & 18.5628 \\
\hline P13(MW) & 12 & 40 & 12.0188 & 40.0000 & 39.9635 & 29.4494 & 20.6263 \\
\hline V1 (p.u) & 0.95 & 1.1 & 1.0847 & 1.0600 & 1.0641 & 1.0065 & 1.0775 \\
\hline V2 (p.u) & 0.95 & 1.1 & 1.0654 & 1.0565 & 1.0584 & 1.0027 & 1.0617 \\
\hline V5 (p.u) & 0.95 & 1.1 & 1.0335 & 1.0376 & 1.0363 & 1.0177 & 1.0708 \\
\hline V8 (p.u) & 0.95 & 1.1 & 1.0381 & 1.0434 & 1.0437 & 1.0098 & 1.0535 \\
\hline V11(p.u) & 0.95 & 1.1 & 1.0843 & 1.0998 & 1.0959 & 1.0289 & 1.0873 \\
\hline V13(p.u) & 0.95 & 1.1 & 1.0453 & 1.0650 & 1.0533 & 1.0102 & 1.0413 \\
\hline T11 & 0.9 & 1.1 & 1.0279 & 1.0733 & 1.0479 & 1.0387 & 1.0166 \\
\hline T12 & 0.9 & 1.1 & 0.9361 & 0.9315 & 0.9307 & 0.9060 & 0.9579 \\
\hline $\mathrm{T} 15$ & 0.9 & 1.1 & 0.9757 & 0.9999 & 0.9923 & 0.9910 & 0.9472 \\
\hline T36 & 0.9 & 1.1 & 0.9756 & 0.9825 & 0.9860 & 0.9714 & 0.9608 \\
\hline QC10 (MVAR) & 0 & 5 & 2.3262 & 2.7505 & 1.4101 & 4.8911 & 1.6256 \\
\hline QC12 (MVAR) & 0 & 5 & 3.9324 & 0.7183 & 3.6882 & 4.3993 & 0.2223 \\
\hline QC15 (MVAR) & 0 & 5 & 4.4115 & 2.6664 & 3.2613 & 4.7698 & 0.9287 \\
\hline QC17 (MVAR) & 0 & 5 & 2.9116 & 1.6783 & 2.7524 & 1.7478 & 0.7723 \\
\hline QC20 (MVAR) & 0 & 5 & 4.6717 & 3.7098 & 1.5721 & 4.9801 & 3.6823 \\
\hline QC21 (MVAR) & 0 & 5 & 4.9008 & 1.9602 & 4.9354 & 4.8403 & 2.6649 \\
\hline QC23 (MVAR) & 0 & 5 & 3.5063 & 3.8141 & 4.7714 & 4.9578 & 1.9901 \\
\hline QC24 (MVAR) & 0 & 5 & 4.8725 & 4.9986 & 4.6153 & 4.9911 & 0.6793 \\
\hline QC29 (MVAR) & 0 & 5 & 2.6080 & 2.9194 & 3.1888 & 3.5958 & 0.1264 \\
\hline Total cost $(\$ / \mathrm{h})$ & - & - & \begin{tabular}{|l|}
800.5454 \\
\end{tabular} & 944.2521 & 967.4142 & 874.4066 & 807.3090 \\
\hline Emissions & - & - & 0.3664 & 0.2048 & 0.2073 & 0.2366 & 0.3264 \\
\hline PLoss (MW) & - & - & 9.0574 & 3.2715 & 3.1225 & 6.2241 & 8.5690 \\
\hline VD & - & - & 0.9215 & 0.8260 & 0.8736 & 0.0924 & 0.8711 \\
\hline L_index & - & - & 0.1384 & 0.1394 & 0.1394 & 0.1491 & 0.1370 \\
\hline
\end{tabular}

are detail descibled in Table 3. From Table 3, it can be noted that, the total generator cost (case 1) is achieved $800.5454(\$ / \mathrm{h})$ using AEO algorithm, which is better than EO, PSO, SFO and GA methods. The total generator achieved of EO method is $800.6220(\$ / \mathrm{h})$, PSO method is $800.5924(\$ / \mathrm{h})$, SFO method is $805.3635(\$ / \mathrm{h})$ and GA method is 800.7742 $(\$ / \mathrm{h})$. The convergence rate of the fuel cost function and obtained value in 50 runs using the AEO and other methods are demonstrated in Fig. 2, Fig.3. As observed from those Figure, ability convergence and standard deviation of AEO algorithm is better than compared with EO, PSO, SFO and GA methods in term of optimal value. For case 2, total emission of AEO approach is approximate EO, PSO approach and is reduced than SFO, GA method as shown in Table 3. The AEO, EO, PSO approaches are total emission 0.2048 (ton $/ \mathrm{h}$ ), while SFO and GA algorithm is 0.2163 (ton/h) and 0.2050 (ton/h) respectively. As noted in Fig. 4, the standard deviation in 50 runs of the AEO algorithm is better than compared with the PSO, SFO and GA method and similar as the EO method.

With case 3, as shown in Table 3, the active power losses is decreased to 3.1225 (MW) using the AEO. From Table 3, it can be seen that, the total 
Table 3. The results obtained of AEO method compared with EO, PSO, SFO and GA method with case 1-5

\begin{tabular}{|c|c|c|c|c|}
\hline Case 1 & \multicolumn{4}{|c|}{ Fuel Cost (\$/h) } \\
\hline Algorithm & Min & Average & Max & Standard deviation \\
\hline $\mathrm{AEO}$ & 800.5454 & 800.6614 & 800.9169 & 0.0742 \\
\hline EO & 800.6220 & 801.2520 & 808.3032 & 1.1501 \\
\hline PSO & 800.5924 & $3.8412 \times 10^{7}$ & $1.2888 \times 10^{8}$ & $3.1887 \times 10^{15}$ \\
\hline SFO & 805.3635 & 909.4241 & $5.2008 \times 10^{3}$ & 619.4435 \\
\hline GA & 800.7742 & 802.2623 & 806.8618 & 1.4086 \\
\hline Case 2 & \multicolumn{4}{|c|}{ Emission (Ton/h) } \\
\hline $\mathrm{AEO}$ & 0.2048 & 0.2049 & 0.2052 & $6.1577 \times 10^{-5}$ \\
\hline $\mathrm{EO}$ & 0.2048 & 0.2049 & 0.2051 & $4.5183 \times 10^{-5}$ \\
\hline PSO & 0.2048 & $3.6719 \times 10^{7}$ & $1.2698 \times 10^{7}$ & $5.4718 \times 10^{7}$ \\
\hline SFO & 0.2163 & 0.2525 & 0.3101 & 0.0238 \\
\hline GA & 0.2050 & 0.2060 & 0.2076 & $6.6487 \times 10^{-4}$ \\
\hline Case 3 & \multicolumn{4}{|c|}{ Power Loss (MW) } \\
\hline $\mathrm{AEO}$ & 3.1225 & 3.1980 & 3.3315 & 0.0505 \\
\hline $\mathrm{EO}$ & 3.1048 & 3.3008 & 4.6138 & 0.2358 \\
\hline PSO & 3.1012 & $3.1781 \times 10^{7}$ & $1.2789 \times 10^{8}$ & $5.2204 \times 10^{7}$ \\
\hline SFO & 4.8875 & $2.0842 \times 10^{3}$ & $1.0389 \times 10^{5}$ & $1.4691 \times 10^{4}$ \\
\hline GA & 3.1847 & 3.4366 & 5.2477 & 0.2927 \\
\hline Case 4 & \multicolumn{4}{|c|}{ Voltage deviation } \\
\hline $\mathrm{AEO}$ & 0.0924 & 0.1000 & 0.1149 & 0.0060 \\
\hline EO & 0.1018 & 0.1207 & 0.1564 & 0.0140 \\
\hline PSO & 0.0904 & $4.1989 \times 10^{7}$ & $1.3034 \times 10^{8}$ & $5.6051 \times 10^{7}$ \\
\hline SFO & 0.2108 & $8.8620 \times 10^{3}$ & $4.4308 \times 10^{5}$ & $6.2661 \times 10^{4}$ \\
\hline GA & 0.1183 & $6.7222 \times 10^{4}$ & $3.3611 \times 10^{6}$ & $4.7533 \times 10^{5}$ \\
\hline Case 5 & \multicolumn{4}{|c|}{ L_index } \\
\hline AEO & 0.1370 & 0.1376 & 0.1388 & $4.0761 \times 10^{-4}$ \\
\hline $\mathrm{EO}$ & 0.1372 & 0.1388 & 0.1408 & $8.2925 \times 10^{-4}$ \\
\hline PSO & 0.1373 & $4.0918 \times 10^{7}$ & $1.2667 \times 10^{8}$ & $5.5296 \times 10^{7}$ \\
\hline SFO & 0.1399 & 0.1454 & 0.1562 & 0.0043 \\
\hline GA & 0.1380 & 0.1406 & 0.1474 & 0.0017 \\
\hline
\end{tabular}

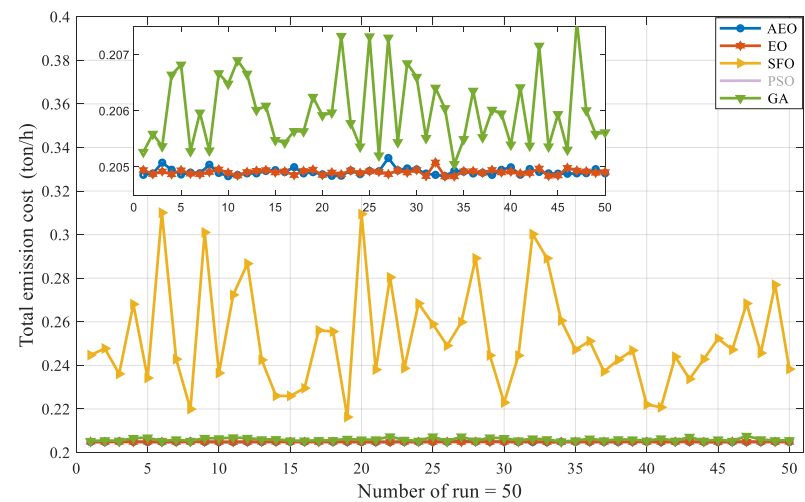

Figure 4. Emission obtained in 50 runs using AEO and other methods

power loss of the AEO technique achieves better minimum compared with the SFO and GA methods. Although power loss obtained from AEO is less than EO and PSO method, however the AEO algorithm has better average and standard deviation values compared with EO and PSO method. This shows the suggested method's effective wih ability to obtain optimized solution as shown in Fig. 5. Also, Fig. 6,

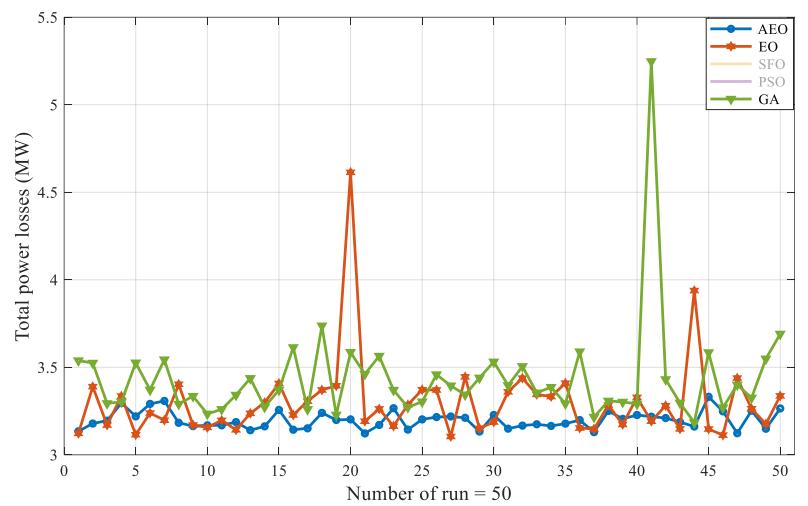

Figure 5. Power loss obtained in 50 runs using AEO and other methods

Fig. 7 are presented obtained values in 50 runs of the AEO method for case 4 and case 5 , respectively. It can be observed that from the Table 3 and those Fig, the AEO algorithm can obtained better voltage deviation and $\mathrm{L} \_$index values with smaller standard deviation compared to EO, PSO, SFO and GA methods. Furthermore, the results simulation show that application of the AEO for the OPF problem that 


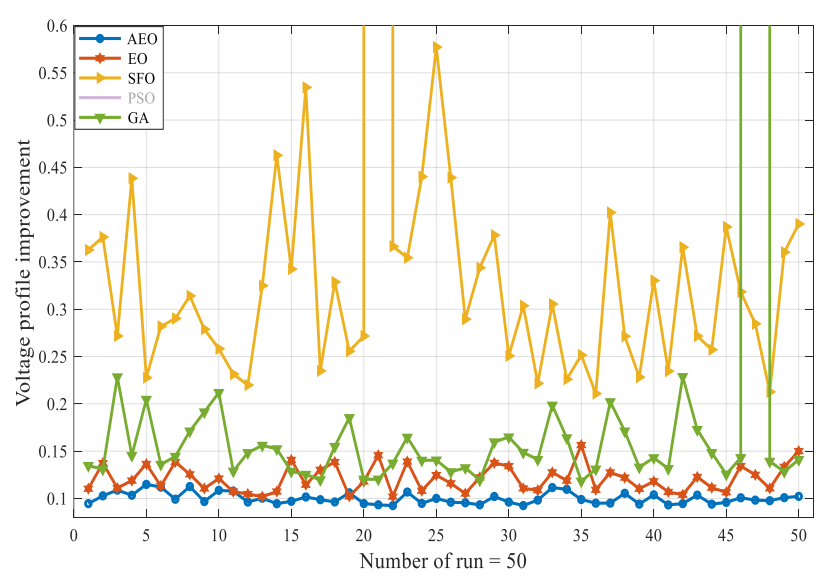

Figure 6. Voltage profile obtained in 50 runs using AEO and other methods

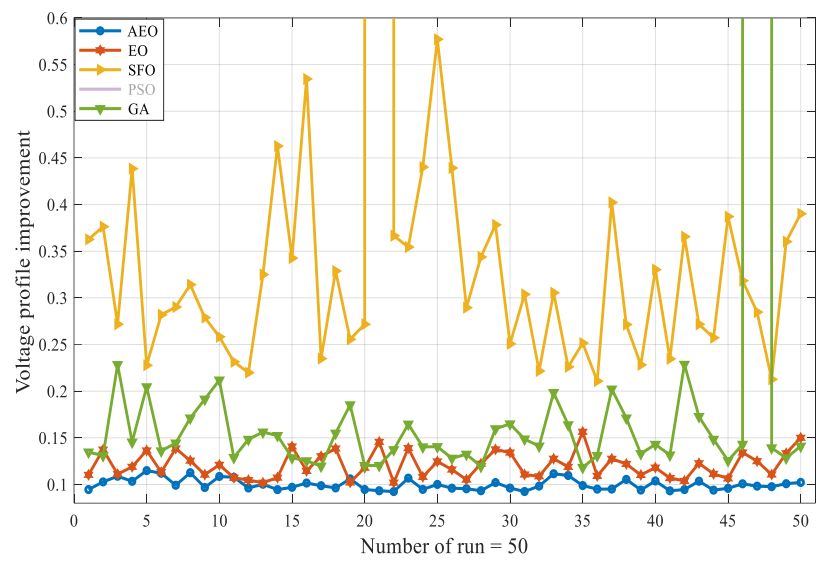

Figure 7. L_index obtained in 50 runs using AEO and other methods

Table 4. The solution obtained from AEO for fuel cost objective compared with different algorithms

\begin{tabular}{llc}
\hline Method & Fuel Cost $(\$ / \mathrm{h})$ & IL $(\%)$ \\
\hline Initial & 901.6391 & 11.21 \\
TS [6] & 802.29 & 0.217 \\
EP [7] & 802.62 & 0.258 \\
DE [8] & 801.23 & 0.085 \\
TLOA [10] & 800.7257 & 0.022 \\
SKHA [11] & 801.4675 & 0.115 \\
MDEA [18] & 802.375 & 0.228 \\
IGWO [22] & 801.259 & 0.089 \\
MSFLA [23] & 802.287 & 0.217 \\
HPSO-DE [28] & 802.248 & 0.212 \\
Proposed AEO & 800.5454 & - \\
\hline
\end{tabular}

Table 5. The solution obtained from AEO for emission objective compared with different algorithms

\begin{tabular}{llc}
\hline Method & Emission (Ton/h) & IL (\%) \\
\hline Initial & 0.3661 & 44.06 \\
SKHA [11] & 0.20508 & 0.136 \\
ABCA [14] & 0.204826 & 0.127 \\
MSA [15] & 0.20482 & 0.010 \\
ARCBOA [20] & 0.2048 & 0 \\
ISKHA [21] & 0.204818 & 0.009 \\
Proposed AEO & 0.2048 & - \\
\hline
\end{tabular}

Table 6. The solution obtained from AEO for TPL objective compared with different algorithms

\begin{tabular}{llc}
\hline Method & TPL (MW) & IL (\%) \\
\hline Initial & 5.830 & 46.44 \\
DE [8] & 3.38 & 7.618 \\
SKHA [11] & 3.1409 & 0.586 \\
ABCA [14] & 3.1078 & 0 \\
EGA [19] & 3.2008 & 2.446 \\
ARCBOA [20] & 3.1009 & 0 \\
Proposed AEO & 3.1225 & - \\
\hline
\end{tabular}

Table 7. The solution obtained from AEO for voltage deviation objective compared with different algorithms

\begin{tabular}{llc}
\hline Method & VD $(\mathrm{Pu})$ & IL $(\%)$ \\
\hline Initial & 1.1747 & 92.13 \\
GWO [8] & 0.118736 & 22.18 \\
BOA [9] & 0.0951 & 2.839 \\
GSA [13] & 0.0932 & 0.858 \\
Jaya [16] & 0.1273 & 27.41 \\
EGA [19] & 0.911 & 89.85 \\
ARCBOA [20] & 0.092 & 0 \\
ISKHA [21] & 0.1029 & 10.20 \\
MICA [24] & 0.0952 & 2.941 \\
MABC [25] & 0.1017 & 9.145 \\
IEMA [26] & 0.1063 & 13.07 \\
SCA [27] & 0.1082 & 14.60 \\
MSCA [27] & 0.103 & 10.29 \\
HPSO-GSA [29] & 0.1267 & 27.07 \\
Proposed AEO & 0.0924 & - \\
\hline
\end{tabular}

Table 8. The solution obtained from AEO for L_index objective compared with different algorithms

\begin{tabular}{llc}
\hline Method & L index $(\mathrm{Pu})$ & IL $(\%)$ \\
\hline ABCA [14] & 0.1379 & 0.652 \\
ARCBOA [20] & 0.1369 & 0 \\
Proposed AEO & 0.1370 & - \\
\hline
\end{tabular}

significantly enhances the performance of power systems. The fuel cost, emissions, active power loss and voltage deviations levels are reduced by $11.21 \%$, $44.06 \%, 46.44 \%$, and $92.13 \%$ respectively, compared to the initial case.

With the purpose of evaluate effective of the susgested AEO method, the authors compare the objective functions including of fuel cost, emission, power loss, voltage deviations and $\mathrm{L} \_$index from the suggested AEO approach to those other methods. The best values achieved for the objectives using the proposed technique and other technique are listed in Table 4-8.

As observed in the Table 4, total fuel cost achieved using the AEO method is reduced insignificantly as compared with TS [6], EP [7], DE [8], TLOA [10], SKHA [11], MDEA [18], IGWO [22], MSFLA [23], and HPSO-DE [28] approaches. The improvement level (IL) in \% can be up to $0.2285 \%$ for fuel cost objective. The four other 
objectives including emission, power loss, voltage deviation and $\mathrm{L}$ index using the AEO have obtained value better or equal compared with diffrent approaches as seen in Table 5-7, respectively. The improvement level percentage of the proposed AEO algorithm to $0.137 \%$ for emission objective, $7.618 \%$ for total power loss objective, $89.85 \%$ for voltage deviation objective and $0.652 \%$ for $\mathrm{L} \_$index objective. The comparison results indicates that the ability quickly convergence of AEO technique with the optimal value. This is demonstration the robust of the AEO technique in dealing with OPF problem.

\section{Conclusion}

OPF is one of important issues for operating of power system and it might be challenging for many algorithms to handle with OPF problem, especially in complex systems. In this paper, the AEO is successfully adjusted for handling the problem of OPF with five other target functions. The optimal values and success rate obtained by the proposed AEO algorithm are the better or same ompared with EO, PSO, SFO and GA method. Furthermore, the fuel cost, emissions, active power loss and voltage deviations levels are reduced by $11.21 \%, 44.06 \%$, $46.44 \%$, and $92.13 \%$ respectively, compared to the initial case. For other exiting methods, the improvement level percentage (IL) of the proposed AEO algorithm can be up to $0.2285 \%$ for fuel cost objective, $0.137 \%$ for emission objective, $7.618 \%$ for total power loss objective, $89.85 \%$ for voltage deviation objective and $0.652 \%$ for L_index objective. The simulation results demonstrate that, the AEO also is one of effective and reliable methods for dealing problem of OPF in large scale and complex systems such as the OPF problem incorporting renewable rnergy, FACTS.

\section{Conflicts of interest}

The authors declare no conflict of interest.

\section{Author contributions}

Conceptualization, T.L.D; methodology, T.L.D; software, N.A.N; validation, T.L.D, N.A.N, and T.T.N; formal analysis, T.L.D and T.T.N; investigation, N.A.N; writing-original draft preparation, T.L.D; writing-review and editing, T.L.D; visualization, N.A.N; supervision, T.L.D

\section{References}

[1] R. M. Palomino and V. H. Quintana, "Sparse Reactive Power Scheduling by a PenaltyFunction Linear Programming Technique",
IEEE Transaction on Power System, Vol. 1, No. 3, pp. 31-39, 1986.

[2] O. Alsac and B. Scott, "Optimal Load Flow with Steady State Security", IEEE Transaction on Power Apparatus and System, Vol. 93, No. 3, pp. 745-751.

[3] D. I. Sun, B. Ashley, B. Brewer, A. Hughes, and W. F. Tinney, "Optimal Power Flow by Newton Approach", IEEE Transaction on Power Apparatus and System, Vol. 103, No. 10, pp. 2864-2875, 1984.

[4] R. C. Burchett, H. H. Happ and D. R. Vierath, "Quadratically Convergent Optimal Power Flow", IEEE Transaction on Power Apparatus and System, Vol. 103, No. 11, pp. 3267-3276, 1984.

[5] X. Yan and V. H. Quintana, "Improving an Interior Point Based OPF by Dynamic Adjustments of Step Sizes and Tolerances", IEEE Transaction on Power System, Vol. 14, No. 2, pp. 709-717, 1999.

[6] M. A. Abido, "Optimal Power Flow Using Tabu Search Algorithm", Electric Power Components System, Vol. 30, No. 5, pp. 469-483, 2002.

[7] Y. Jason and P. W. Kit, "Evolutionary Programming Based Optimal Power Flow Algorithm", IEEE Transactions on Power Systems, Vol. 14, No. 4, pp. 1245-1250,1999.

[8] A. A. E. Fergany and H. M. Hasanien, "Single and Multi-Objective Optimal Power Flow Using Grey Wolf Optimizer and Differential Evolution Algorithms", Electric Power Components System, Vol. 43, No. 13, pp. 1548-1559, 2015.

[9] A. Bhattacharya and P. K. Chattopadhyay, "Application of Biogeography-Based Optimisation to Solve Different Optimal Power Flow Problems", IET Generator Transmission Distribution, Vol. 5, No. 1, pp. 70-80, 2011.

[10] M. R. Nayak, C. K. Nayak, and P. K. Rout, "Application of Multi-Objective Teaching Learning Based Optimization Algorithm to Optimal Power Flow Problem", Procedia Technology, Vol. 6, pp. 255-264, 2012.

[11] H. Pulluri, R. Naresh, and V. Sharma, "A Solution Network Based on Stud Krill Herd Algorithm for Optimal Power Flow Problems", Soft Computer, Vol. 22, No. 1, pp. 159-176, 2018

[12] M. Siva1, R. Balamurugan, and L. Lakshminarasimman, "Water Wave Optimization Algorithm for Solving Economic Dispatch Problems with Generator Constraints", International Journal of Intelligent Engineering and Systems, Vol. 9, No. 4, pp. 31-40, 2016.

[13] S. Duman, U. Güvenc, Y. So"nmez, and N. 
Yo"ru"keren, "Optimal Power Flow Using Gravitational Search Algorithm", Energy Convers Manager, Vol. 59, No. 7, pp. 86-95, 2012.

[14] M. R. Adaryani and A. Karami, "Artificial Bee Colony Algorithm for Solving Multi-Objective Optimal Power Flow Problem", International Journal Electric Power Energy System, Vol. 53, No. 13, pp. 219-230, 2013.

[15] A. A. A. Mohamed, Y. S. Mohamed, A. A. E. Gaafary, and A. M. Hemeida, "Optimal Power Flow Using Moth Swarm Algorithm", Electric Power System Resarch, Vol. 142, No. 1, pp. 190206, 2017.

[16] W. Warid, H. Hizam, N. Mariun, and N. I. A. Wahab, "Optimal Power Flow Using the Jaya Algorithm", Energies, Vol. 9, No. 9, pp. 678, 2016.

[17] C. Thitithamrongchai and B. E. Arporn, "SelfAdaptive Differential Evolution Based Optimal Power Flow for Units with Nonsmooth Fuel Cost Functions", Journal Electric System, Vol. 3, No. 2, pp. 88-99, 2007.

[18] S. Sayah and K. Zehar, "Modified Differential Evolution Algorithm for Optimal Power Flow with Non-smooth Cost Functions", Energy Convers Manager, Vol. 49, No. 11, pp. 30363042, 2008.

[19] M. S. Kumari and S. Maheswarapu, "Enhanced genetic algorithm based computation technique for multi-objective optimal power flow solution", International Journal Electric Power Energy System, Vol. 32, No. 6, pp. 736-742, 2010.

[20] A. R. Kumar, and L. Premalatha, "Optimal Power Flow for a Deregulated Power System Using Adaptive Real Coded BiogeographyBased Optimization", International Journal Electric Power Energy System, Vol. 73, No. 12 , pp. 393-399, 2015.

[21] G. Chen, Z. Lu, and Z. Zhang, "Improved Krill Herd Algorithm with Novel Constraint Handling Method for Solving Optimal Power Flow Problems", Energies, Vol. 11, No. 1, pp. 76, 2018.

[22] M. Abdo, S. Kamel, M. Ebeed, J. Yu, and F. Jurado, "Solving Nonsmooth Optimal Power Flow Problems Using a Developed Grey Wolf Optimizer", Energies, Vol. 11, No. 7, pp. 1692, 2018.

[23] T. Niknam, M. R. Narimani, M. Jabbari, and A. R. Malekpour, "A Modified Shuffle Frog Leaping Algorithm for Multi-Objective Optimal Power Flow", Energy, Vol. 36, No. 11, pp. 64206432, 2011.
[24] A. K. Murtadha and A. B. Layth, "Modified Artificial Bee Colony Optimization Technique with Different Objective Function of Constraints Optimal Power Flow", International Journal of Intelligent Engineering and Systems, Vol. 13, No. 4, pp. 378-388, 2020

[25] M. Ghasemi, S. Ghavidel, M. M. Ghanbarian, M. Gharibzadeh, and A. A. Vahed, "MultiObjective Optimal Power Flow Considering the Cost, Emission, VD and TPL Using MultiObjective Modified Imperialist Competitive Algorithm", Energy, Vol. 78, pp. 276-289, 2014.

[26] H. R. E. H. Bouchekara, M. A. Abido, and A. E. Chaib, "Optimal Power Flow Using an Improved Electromagnetism-Like Mechanism Method", Electric Power Components System, Vol. 44, No. 4, pp. 434-449, 2016.

[27] A. F. Attia, R. A. E. Sehiemy, and H. M. Hasanien, "Optimal Power Flow Solution in Power Systems Using a Novel Sine-Cosine Algorithm", International Journal Electric Power Energy System, Vol. 99, No. 7, pp. 331343, 2018.

[28] P. M. Le, T. L. Duong, D. N. Vo, T. T. Le, and S. Q. Nguyen, "An Efficient Hybrid Method for Solving Security-Constrained Optimal Power Flow Problem", International Journal on Electrical Engineering and Informatics, Vol. 12, No. 4, pp. 933-955, 2020.

[29] J. Radosavljević, D. Klimenta, M. Jevtić, and N. Arsić, "Optimal Power Flow Using a Hybrid Optimization Algorithm of Particle Swarm Optimization and Gravitational Search Algorithm", Electric Power Components and Systems, Vol. 43, No. 17, pp. 1958-1970, 2015.

[30] W. Zhao, L. Wang, and Z. Zhang, "Artificial Ecosystem-Based Optimization: A Novel Nature-Inspired Meta-Heuristic Algorithm", Neural Computing and Applications, Vol. 32, No. 13, pp. 9383-9425, 2020.

[31] S. Mouassa, F. Jurado, T. Bouktir, M. A. Z. Raja, "Novel Design of Artificial Ecosystem Optimizer for Large-Scale Optimal Reactive Power Dispatch Problem with Application to Algerian Electricity Grid", Neural Computing and Applications, Vol. 33, pp. 7467-7490, 2021.

[32] R. D. Zimmerman, M. Sa'nchez, and R. J. Thomas, https://www.pserc.cornell.edu/ matpower, Accessed 1, 2018.

\section{Appendix}

\begin{tabular}{|l|l|}
\hline \multicolumn{2}{|l|}{ Nomenclature and abbreviations } \\
\hline $\mathrm{P}_{\mathrm{G}, \text { slack }}$ & active power of the slack generator \\
\hline $\mathrm{V}_{\mathrm{L}}$ & magnitude voltage of the load bus \\
\hline
\end{tabular}




\begin{tabular}{|l|l|}
\hline$Q_{G}$ & reactive power of the generators \\
\hline $\mathrm{S}_{\mathrm{l}}$ & transparent power flow in line \\
\hline $\mathrm{P}_{\mathrm{G}}$ & active power of the generator \\
\hline $\mathrm{T}_{\mathrm{k}}$ & tap changer of the transformer \\
\hline $\mathrm{Q}_{\mathrm{C}}$ & reactive power of shunt compensator \\
\hline $\mathrm{V}_{\mathrm{G}}$ & magnitude voltage of the generator bus \\
\hline $\mathrm{N}$ & Toal number of buses \\
\hline $\mathrm{N}_{\mathrm{L}}$ & number of load buses. \\
\hline $\mathrm{N}_{\mathrm{G}}$ & number of generating units \\
\hline $\mathrm{N}_{\mathrm{T}}$ & number of regulating transformers. \\
\hline $\mathrm{N}_{\mathrm{l}}$ & number of line. \\
\hline $\mathrm{N}_{\mathrm{c}}$ & number of shunt compensators \\
\hline $\mathrm{V}_{\mathrm{i}, \mathrm{V}} \mathrm{V}_{\mathrm{j}}$ & magnitude voltages of the buses $\mathrm{i}, \mathrm{j}$. \\
\hline $\mathrm{P}_{\mathrm{i}}$ & active power injection into $i$ th bus \\
\hline $\mathrm{Q}_{\mathrm{i}}$ & reactive power injection into $i$ th bus \\
\hline $\mathrm{P}_{\mathrm{Gi}}$ & active generated at bus $\mathrm{i}$ \\
\hline $\mathrm{Q}_{\mathrm{Gi}}$ & reactive power generated at bus $\mathrm{i}$ \\
\hline $\mathrm{P}_{\mathrm{Dj}}$ & load active power at bus $\mathrm{j}$ \\
\hline $\mathrm{Q}_{\mathrm{Dj}}$ & load reactive power at bus $\mathrm{i}$ \\
\hline $\mathrm{P}_{\mathrm{Gi}, \min }$ & min. active power limit of generator \\
\hline $\mathrm{Q}_{\mathrm{Gi}, \min }$ & min. reactive power limit of generator \\
\hline $\mathrm{P}_{\mathrm{Gi}, \max }$ & max. active power limit of generator \\
\hline $\mathrm{Q}_{\mathrm{Gi}, \max }$ & max. reactive power limit of generator \\
\hline $\mathrm{V}_{\mathrm{Gi}, \min }$ & min. voltage of the generator bus $\mathrm{i}$ \\
\hline $\mathrm{V}_{\mathrm{Gi}, \max }$ & max. voltage of the generator bus $\mathrm{i}$ \\
\hline $\mathrm{V}_{\mathrm{Li}, \min }$ & min. voltage of the load bus $\mathrm{i}$ \\
\hline $\mathrm{V}_{\mathrm{Li}, \max }$ & max. voltage of the load bus $\mathrm{i}$ \\
\hline $\mathrm{Q}_{\mathrm{ci}, \min }$ & $\begin{array}{l}\text { min. reactive power compensative devise at } \\
\text { load bus i }\end{array}$ \\
\hline $\mathrm{Q}_{\mathrm{ci}, \max }$ & $\begin{array}{l}\text { max. reactive power compensative devise at } \\
\text { load bus } \mathrm{i}\end{array}$ \\
\hline $\mathrm{T}_{\mathrm{i}, \min }$ & min. tap changer of the transformer \\
\hline $\mathrm{T}_{\mathrm{i}, \max }$ & max. tap changer of the transformer \\
\hline $\mathrm{S}_{\mathrm{l}, \max }$ & max. line flow limits of transmission line \\
\hline
\end{tabular}

